\title{
"In-situ" lipase-catalyzed cotton coating with polyesters from ethylene glycol and glycerol
}

\author{
Xiaoman Zhao ${ }^{\mathrm{a}, \mathrm{b}}$, Jennifer Noro ${ }^{\mathrm{c}}$, Jiajia Fu ${ }^{\mathrm{a}, \mathrm{d}}$, Hongbo Wang ${ }^{\mathrm{a}}$, Carla Silva ${ }^{\mathrm{c}}$, \\ Artur Cavaco-Paulo ${ }^{\mathrm{b}, \mathrm{c}, *}$ \\ a Jiangsu Engineering Technology Research Center for Functional Textiles, Jiangnan University, Wuxi, 214122, PR China \\ ${ }^{\mathrm{b}}$ International Joint Research Laboratory for Textile and Fiber Bioprocesses, Jiangnan University, Wuxi, 214122, PR China \\ ' Centre of Biological Engineering, University of Minho, Campus de Gualtar, Braga, 4710-057, Portugal \\ d National Engineering Laboratory for Modern Silk, Soochow University, Suzhou, 215123, PR China
}

\section{A R T I C L E I N F O}

\section{Keywords:}

Immobilized Candida antarctica lipase B

Polymerization

Conversion rate

Lipase from Thermomyces lanuginosus

In situ lipase-catalyzed polymerization

Cotton

\begin{abstract}
A B S T R A C T
Several polyesters were synthesized from ethylene glycol, glycerol and adipate, succinate dimethyl esters. Immobilized Candida antarctica lipase B was used as catalyst for $6 \mathrm{~h}$ under vacuum at $70^{\circ} \mathrm{C}$ without any further solvents. The highest conversion rate of $88.5 \%$ occurred for the polymerization of poly(ethylene adipate), evaluated by ${ }^{1} \mathrm{H}$ NMR. MALDI-TOF analysis indicated that most of the oligomers formed were dimers or trimers. After successfully synthesize the polyesters we set-up the optimal conditions for their in-situ coating onto cotton substrates with a soluble lipase from Thermomyces lanuginosus. This work presents a novel bio-approach to impart hydrophobic properties to coated cotton-based fibre materials.
\end{abstract}

\section{Introduction}

Synthesis of complex and well-defined polymers is required to meet the environmentally friendly concept of green chemistry and of the sustainable chemical industry [1]. Therefore, enzymatic polymerization, especially the lipase-catalyzed synthesis of aliphatic polyesters, has been promptly developed as an important synthetic technique of polymerization. [2,3]. The enzymatic polymerization presents several advantages when compared with conventional routes, such as mild reaction conditions, wide-range substrate specificity, high control of enantio-, chemo-, and region-selectivity, few by-products and high catalytic activity $[4,5]$. Most of the known aliphatic polyesters can be regarded as biobased polymers [6,7] as the majority of the starting reactants can be obtained from biomass feedstock. Aliphatic polyesters have superior biodegradability, biocompatibility and probable bioresorbability, and can be applied to diverse potential fields like textiles manufacturing $[5,8]$, food packaging as well as biomedical and pharmaceutical fields [5,9-12]. The enzymatic polymerization of aliphatic polyesters has been considered therefore as a promising alternative to the traditional chemical polymerization.

Lipases (triacylglycerol ester hydrolases, E.C. 3.1.1.3) can catalyze both hydrolytic and synthetic reactions in nature. These properties allow them to be employed in a variety of biochemical reactions, including acidolysis, aminolysis, alcoholysis when in an aqueous solution, esterification, transesterification and acylation when in non-aqueous media $[13,14]$. Based on these specific properties, lipases are widely applied as bio-catalysts in the textile field [8], food manufacture [15], biomedical and pharmaceutical industry [16], and energy (biodiesel) production $[17,18]$. Lipases can also be described as bio-catalysts for various organic solvents [19] and emulsions [20]. However, a better polymerization process can be achieved by using a solvent-free enzymatic system without further complex purification process [21,22].

Hydrophobic cellulosic materials are highly demanded considering their specific water-repellent properties. It imparts to the materials a series of excellent functional performances such as hydrophobicity, selfcleaning, antifouling, and friction reduction [8,23,24]. Cotton cellulose holds remarkable advantages when used as substrate for the production of hydrophobic materials. Its biodegradability and unique physical, chemical and mechanical properties are superior to the traditional nonrenewable materials [24,25]. The conventional hydrophobic modification of cotton involves the surface modification using different hydrophobic compounds, such as fluorocarbons [26], silicones [27] and hydrocarbons [23]. Nevertheless, these methods have certain shortcomings related with sustainability and environmental concerns, which in turns urgent to find ecologically greener alternatives [25].

Our previous works reported the lipase-catalyzed synthesis of poly (ethylene glutarate) and the production of hydrophobic cotton by in situ lipase-catalyzed coating with poly(ethylene glutarate) [8,28]. The

\footnotetext{
* Corresponding author: International Joint Research Laboratory for Textile and Fiber Bioprocesses, Jiangnan University, Wuxi 214122, PR China.

E-mail address: artur@deb.uminho.pt (A. Cavaco-Paulo).
} 
results obtained reveal high synthesis conversion levels when immobilized CALB was used. Based on this assumption, the new polyesters were herein produced from the starting reactants ethylene glycol, glycerol and adipate and succinate dimethyl esters, without addition of solvents. The reactions were catalyzed by immobilized Candida antarctica lipase B (CALB) for $6 \mathrm{~h}$ at $70^{\circ} \mathrm{C}$ under vacuum. After the successful production of polyesters, we set-up the optimal conditions for their in situ coating onto cotton fabrics. Mass restrains, due to the use of a solid enzyme and a solid support (cotton fabric), lead us to replace the immobilized enzyme by a liquid catalyst from Thermomyces lanuginosus. An orthogonal experimental design was performed to set-up the optimum conditions for the hydrophobic coating of cotton. The new polyesters were analyzed by ${ }^{1} \mathrm{H}$ NMR and MALDI-TOF spectrometry. The hydrophobicity and the wettability of the coated cotton were evaluated by water contact angle determination and bromophenol blue water-drop test.

\section{Material and methods}

\subsection{Materials}

Fermase CALB ${ }^{\mathrm{TM}} 10,000$, a commercial Candida antarctica lipase B (CALB) immobilized on glycidyl methacrylate-ter-divinylbenzene-terethylene glycol dimethacrylate (particle size of $150-300 \mu \mathrm{m}$, pore volume of $1.32 \mathrm{~cm}^{3} / \mathrm{g}$, bulk density of $0.54 \mathrm{~g} / \mathrm{cm}^{3}$ and an activity of 8000 propyl laurate units) was received as a gift sample from Fermenta Biotech Ltd., Mumbai, India. Lipase from Thermomyces lanuginosus with an activity of over 100,000 U/g was acquired from Sigma-Aldrich, Chemie GmbH., USA. Dimethyl adipate (purity $\geq 99 \%$ ) and dimethyl succinate (purity 99\%) were obtained from Adamas Reagent Co., Ltd, China. Ethylene glycol (AR, purity $\geq 99 \%$ ), glycerol (AR, purity $\geq 99 \%$ ), tetrahydrofuran (AR, purity $\geq 99 \%$ ), petroleum ether (AR, $30{ }^{\circ} \mathrm{C}-60^{\circ} \mathrm{C}$ ), sodium sulfate anhydrous (AR, purity $\geq 99 \%$ ) and methylene blue trihydrate (BS) were purchased from Sinopharm Chemical Reagent Co., Ltd., Shanghai, China. Whatman Filter paper was obtained from Whatman Wohua Co., Ltd., Hangzhou, China. All the chemicals and enzymes were used directly without any further modification.

The bleached cotton fabric $(40 \mathrm{~s} \times 40 \mathrm{~s} / 524 \times 283$ (ends $\times$ picks) and $124 \mathrm{~g} \mathrm{~m}^{-2}$ ) was purchased from Huafang Limited Company, Binzhou City, Shandong Province.

The rotary vacuum evaporator (Vac) (model RV 10 D S73, IKA Works Guangzhou Co., Ltd, Guangzhou, China) equipped with water bath and temperature controller was used in all the reactions. During the experiments, the vacuum bath was operated at $100 \mathrm{rpm}$.

\subsection{CALB-catalyzed synthesis of polyesters}

Poly(ethylene adipate), poly(ethylene succinate), poly(glycerol adipate) and poly(glycerol succinate) were synthesized using ethylene glycol, glycerol, and adipate and succinate dimethyl esters as starting reactants. The reactions were performed for $6 \mathrm{~h}$ at $70{ }^{\circ} \mathrm{C}$ under vacuum using immobilized CALB as catalyst $(1 \%(\mathrm{w} / \mathrm{v}))$. The reaction schemes for polyester synthesis are depicted in Table 1 . The starting reactants for each scheme are, Scheme A': equimolar ratio of ethylene glycol and dimethyl adipate; Scheme B': equimolar ratio of ethylene glycol and dimethyl succinate; Scheme C': equimolar ratio of glycerol and dimethyl adipate; Scheme D': equimolar ratio of glycerol and dimethyl succinate. The total volume of the reaction mixture was $2 \mathrm{~mL}$ without addition of solvents.

\subsection{Purification of the synthesized polyesters}

The purification of the synthesized polyesters took place by adding $3 \mathrm{~mL}$ of tetrahydrofuran (for Reaction Scheme A' and B') and $3 \mathrm{~mL}$ of methanol (for Reaction Scheme C' and D') to the mixture, to dissolve the residual reagents and the synthesized polyesters. Then, the solutions were filtered out using Whatman filter paper, to separate the granular enzyme (CALB) from the reaction products. After evaporating all the tetrahydrofuran/methanol, a mixture of tetrahydrofuran and petroleum ether in the proportion of 1:14 was added. The mixture was kept at $-20^{\circ} \mathrm{C}$ overnight to precipitate the synthesized polyesters. The mixture of polyesters and a slight amount of residual reagents were then collected, after evaporation of the petroleum ether and methanol/tetrahydrofuran. Finally, the collected products were lyophilized and analyzed by ${ }^{1} \mathrm{H}$ NMR and MALDI-TOF [5,28].

\section{4. "In situ" enzymatic coating of cotton fabrics with polyesters: experimental design}

The bleached cotton fabrics were pre-washed for $1 \mathrm{~h}$ with distilled water at $50^{\circ} \mathrm{C}$, dried at room temperature and then kept in a standard atmosphere for at least $48 \mathrm{~h}$ prior to the experiments. The preparation of the starting reactants for each reaction scheme is shown in Table 2. Lipase from Thermomyces lanuginosus in liquid state was used for the enzymatic cotton coating. For each scheme, cotton samples (500 $\pm 0.5 \mathrm{mg}$ ) were evenly soaked with the corresponding prepared reaction mixture using round bottom flasks. The reactions were carried out in a rotary vacuum evaporator for $6 \mathrm{~h}$ at $70^{\circ} \mathrm{C}$. The control was conducted under the same conditions but using deactivated enzyme. All experiments were done in triplicate. After enzymatic coating, all the cotton samples were washed twice with tetrahydrofuran (for Scheme $\mathrm{A}_{0}$ and $\mathrm{B}_{0}$ ) and methanol (for Scheme $\mathrm{C}_{0}$ and $\mathrm{D}_{0}$ ) to remove the remaining reactants at the surface of cotton fabrics and the soluble lipase. Afterwards all the samples were kept inside an extractor hood at room temperature for $8 \mathrm{~h}$ until the complete solvent evaporation.

An orthogonal experiment L9 $(3 \times 3)$ design was carried out to explore the optimum conditions to enzymatically coat "in situ" the cotton fabrics imparting them a hydrophobic behavior. The temperature, enzyme loading and reaction time were chosen as factors. The contact angle was considered as the index. There were considered three levels for each factor basing on the single-factor experiment (Table 3). The experimental design for each reaction scheme was shown in the supplementary material section (Table S6-Table S9).

\section{5. ${ }^{1} \mathrm{H} N M R$ and MALDI-TOF mass spectra of the synthesized polyesters}

The reaction products were dissolved in $500 \mu \mathrm{L}$ of deuterated dimethyl sulfoxide (DMSO- $d_{6}$ ). The ${ }^{1} \mathrm{H}$ NMR spectra were recorded using a Bruker Advance III 400 NMR spectrometer (Bruker Corporation, Germany), $400 \mathrm{MHz}$ at $25^{\circ} \mathrm{C}$. Matrix assisted laser desorption ionization time of flight (MALDI-TOF) mass spectra of the reaction products were obtained by using a microflex LT MALDI-TOF mass spectrometry (Bruker Daltonics GmbH, Germany) equipped with a 337-nm nitrogen laser. The saturated matrix $\alpha$-Cyano-4-hydroxy cinnamic acid (HCCA) was prepared in a solution of $30 \%$ acetonitrile and $0.1 \%$ Trifluoroacetic acid (TFA) in ultra pure water. The samples were prepared in tetrahydrofuran (for Scheme A' and B')/methanol (for Scheme C' and D'). And then the matrix HCCA was mixed with samples (v/v, 1:1). A volume of $1 \mu \mathrm{L}$ of each sample/matrix mixture was deposited on a polished steel target plate (Bruker part $n^{\circ}$ 8280800) and then allowed to dry at room temperature in air. The dried sample spots were analyzed by the positive-ion method of RP300-4000 in the reflective mode.

\subsection{Calculation of the average polymerization degree of synthesized polyesters}

The average degree of polymerization of synthesized polyesters was acquired from the MALDI-TOF mass spectra. For each reaction scheme, we consider three possible different polyesters with different type of end groups like ester and alcohol. All of the possible chemical structures for the formed polyesters are depicted in Table S1 in supplementary 
Table 1

Reaction schemes for polyester synthesis catalyzed by immobilized CALB $(1 \% \mathrm{w} / \mathrm{v})$ for $6 \mathrm{~h}$ at $70^{\circ} \mathrm{C}$ under vacuum.

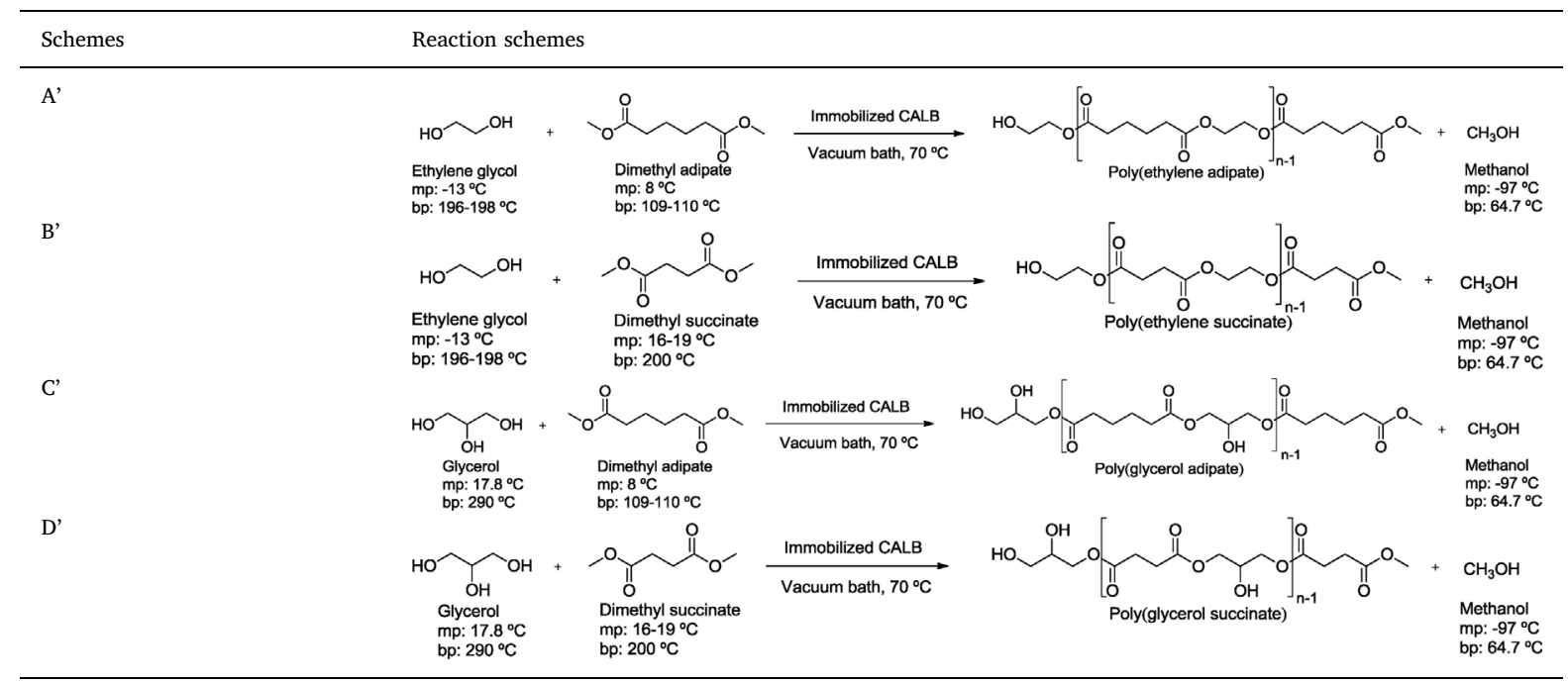

Table 2

Reaction mixtures used for the "in situ" enzymatic cotton coating

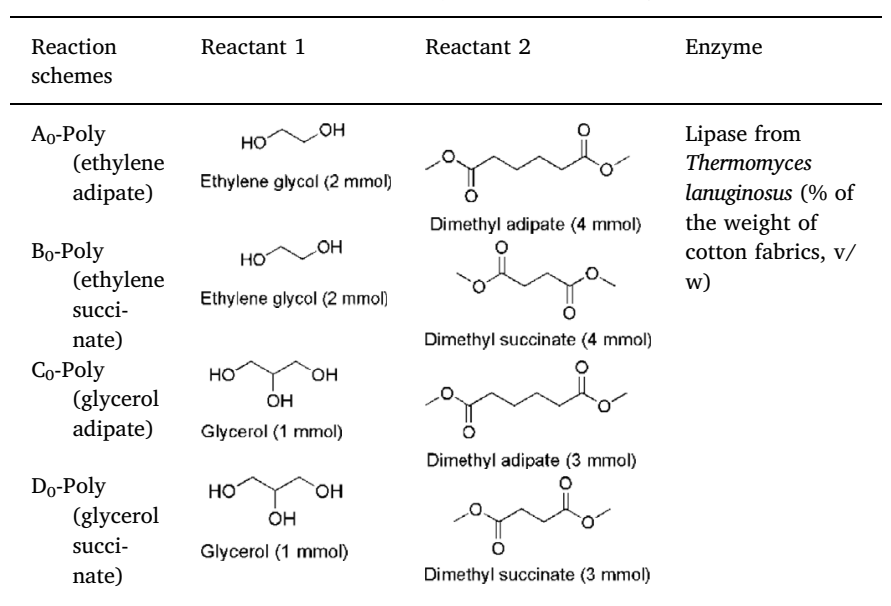

Table 3

Levels/factors in the orthogonal experiment.

\begin{tabular}{llll}
\hline Level & Temperature (A) $\left({ }^{\circ} \mathrm{C}\right)$ & $\begin{array}{l}\text { Enzyme loading (B) (\% v/ } \\
\text { w) }\end{array}$ & Reaction time (C) (h) \\
\hline 1 & 35 & 35 & 4 \\
2 & 45 & 50 & 6 \\
3 & 55 & 65 & 8 \\
\hline
\end{tabular}

materials. The molecular weight of the synthesized polyesters is calculated according to the molecular weight of the repeat units and the degree of polymerization. The formula for calculation of the molecular weight for each polyester is presented in the supplementary materials section (Table S2-Table S5).

The equation used for the calculation of the average degree of polymerization for each reaction scheme is as follows (Eq. (1)) [5].

Average degree of polymerization

$$
=\operatorname{SUM}\left(\frac{\text { Intensity of each peak }}{\text { Sum of intensity of all peaks }} \times \text { Number of repeat units }\right) *
$$

*The sum of relative intensities should be one.
2.7. Water contact angle and bromophenol blue water-drop tests of coated cotton fabrics

The water contact angle of coated cotton samples was measured on a Drop Shape Analyzer (DSA25, KRUSS GmbH, Germany) at room temperature. All the samples were conditioned in a standard atmosphere at room temperature $\left(20^{\circ} \mathrm{C}\right)$ and $65 \%$ of relative humidity for at least $48 \mathrm{~h}$ prior to the testing. The contact angle was acquired by depositing ultra-pure water droplet of $10 \mu \mathrm{L}$ on the surface of cotton samples. All the measurements were made in triplicate [8].

For bromophenol test, colored water was pre-prepared by dissolving a small amount of bromophenol blue dye in distilled water. A droplet of $5 \mu \mathrm{L}$ of the blue water was dripped onto the surface of the modified cotton fabrics to visually evaluate the hydrophobic behavior of the coated cotton.

\section{Results and discussion}

\subsection{MALDI-TOF mass spectra and ${ }^{1} H$ NMR spectra analysis of the synthesized polyesters}

CALB is not as efficient as other lipases in hydrolyzing triglycerides; however, it is highly stereospecific towards both ester hydrolysis and synthesis, probably due to the limited space available in its hydrophobic pocket. In contrast with non-immobilized lipases it offers several advantages like recovery and recycling, choice of batch or continuous process, rapid termination of the reactions, controlled product formation and easy removal from the reaction mixture [29]. Based on these features and on previous data reported by us [28] new poly (ethylene adipate), poly (ethylene succinate), poly (glycerol adipate) and poly (glycerol succinate) were catalyzed by the immobilized CALB at $70{ }^{\circ} \mathrm{C}$ for $6 \mathrm{~h}$ under vacuum.

For each polymerization scheme, one can predict different possibilities of polyester formation with different end groups depending on the starting reactants used (Table S1). One possibility is the formation of a polyester with alcohol and ester as end groups, the other contemplates both alcohols as end groups and finally other with both esters as end groups. The average polymerization degree of the new polyesters was calculated using the weighted mean (See Eq. (1)). The conversion rate of each polymerization reaction was calculated based on the ${ }^{1} \mathrm{H}$ NMR spectra according to the peak variations of the characteristic functional groups (See Eq. (2)). 
Table 4

Polymerization conversion rates and average polymerization degree of the synthesized polyesters.

\begin{tabular}{lllll}
\hline Schemes & $\begin{array}{l}\text { Conversion rate of } \\
\text { polymerization reaction (by } \\
\end{array}$ & $\begin{array}{l}{ }^{1} \text { H NMR mass spectra (\%)) } \\
\text { (1 }\end{array}$ & $\begin{array}{l}\text { Average degree of polymerization } \\
\text { of polyesters (by MALDI-TOF mass } \\
\text { spectra) }\end{array}$ & \\
\cline { 3 - 5 } & & $\mathrm{n}_{\mathrm{ae}}{ }^{1}$ & $\mathrm{n}_{\mathrm{aa}}{ }^{1}$ & $\mathrm{n}_{\mathrm{ee}}{ }^{1}$ \\
\hline $\begin{array}{c}\text { A'-Poly(ethylene } \\
\text { adipate) }\end{array}$ & 86.96 & 2.16 & 2.44 & 1.52 \\
$\begin{array}{c}\text { B'-Poly(ethylene } \\
\text { succinate) }\end{array}$ & 43.48 & 2.60 & 2.10 & 2.22 \\
$\begin{array}{c}\text { C'-Poly(glycerol } \\
\text { adipate) }\end{array}$ & 35.10 & 2.58 & 2.09 & 1.22 \\
$\begin{array}{c}\text { D'-Poly(glycerol } \\
\text { succinate) }\end{array}$ & 6.1 & 2.45 & 2.40 & 1.77 \\
\hline
\end{tabular}

${ }^{1} n_{a e}$ represents the average degree of polymerization of polyester with alcohol and ester as end groups; $n_{a a}$ represents the average degree of polymerization of polyester with alcohols as end groups; $n_{e e}$ represents the average degree of polymerization of polyester with esters as end groups.

Polymerization conversion rate $=\frac{A_{1}}{A_{1}+A_{0}} \times 100 \% *$

* $\mathrm{A}_{0}$ represents the peak integration area of the functional group protons in the remaining starting reagent in the reaction mixture; $A_{1}$ represents the peak integration area of the same functional group protons in the synthesized polyester.

The conversion rate and the average degree of polymerization for each reaction scheme are shown in Table 4. All the NMR spectra and the MALDI-TOF mass spectra are exhibited in supplementary materials (Fig. S1-Fig. S8).

From ${ }^{1} \mathrm{H}$ NMR data presented in Table 4, the polymerization conversion rate of poly(ethylene adipate) (Scheme A') was twice higher than that of poly(ethylene succinate) (Scheme B'). This can be attributed to the alkyl chain length selectivity of lipases, which presented higher activity towards long alkyl chain substrate, dimethyl adipate, than towards dimethyl succinate [30,31]. ${ }^{1} \mathrm{H}$ NMR data of poly(ethylene adipate) (Scheme A') (Fig. S1) shows the decrease of the signal intensity of the protons of ethylene glycol (at $\delta_{\mathrm{H}} 3.36 \mathrm{ppm}$ ) and the appearance of a new peak corresponding to the same protons in the polymer at $\delta_{\mathrm{H}} 4.21 \mathrm{ppm}$. The peaks corresponding to the terminal unit of ethylene glycol (in a form of a triplet instead of singlet) are also detected by NMR, confirming the synthesis of the new polymer. For Scheme B' the ${ }^{1} \mathrm{H}$ NMR presents the same behavior (Fig. S2).
The conjugation effect of the adipate and succinate dimethyl esters can both influence negatively the enzymatic polymerization reactions [32]. However, dimethyl adipate reacted more easily than dimethyl succinate maybe due to its lower polarity. The weakened conjugation effect endowed a less stability of the ester bonds being, dimethyl adipate more easily captured by the active site of lipase, subsequently becoming the reactive intermediate by protonation or ionization [32,33].

From comparison of the conversion rates of Table 4 one can establish that the polymerization from ethylene glycol (Scheme A' and Scheme B') seemed to be more prone to react than those from glycerol (Scheme C' and Scheme D'). The polarity of ethylene glycol is lower than that of glycerol, which contributed to the easy combination of ethylene glycol with the active site of lipase [32]. ${ }^{1} \mathrm{H}$ NMR spectra of both poly (glycerol adipate) and poly (glycerol succinate) present the decrease of the signal intensity of the protons of glycerol (between $\delta_{\mathrm{H}}$ 3.3-3.5 ppm) and the appearance of new peaks corresponding to the same protons in the new polymers at (between $\delta_{\mathrm{H}} 3.8-5 \mathrm{ppm}$ ). The conversion rate of poly (glycerol succinate) is much lower than poly (glycerol adipate) which can be confirmed by the large amount of unreacted glycerol (between $\delta_{\mathrm{H}} 3.3-3.5 \mathrm{ppm}$ ) (Figs. S3 and S4).

It can also be highlighted that CALB predominantly catalyzed the polymerization of oligomers with low average polymerization degree (DP), confirmed by MALDI-TOF mass spectra. Form all the oligomers synthesized, the ones containing ester and alcohol as end groups presented the highest average DP (i.e. $\mathrm{n}_{\mathrm{ae}}$ in Table 4) on account of the equivalent molar ratio of reactants in the reaction systems.

Previous studies related with polyester synthesis reported high values of polymerization degree and conversion rate. However the reactions involved the use of organic solvents or were assisted by ultrasounds [28,34]. Our study is thus a step forward for the enzymatic synthesis of polyesters in the absence of organic solvents.

\section{2. "In situ" coating of cotton with the synthesized polyesters}

The "in situ" coating of cotton with the new polyesters was performed using liquid lipase from Thermomyces lanuginosus as catalysts, under vacuum $[28,35]$ and considering the reaction conditions exemplified in Fig. 1. As mentioned in the introduction section, it was imperative to replace the enzyme in the solid form by a liquid one. The adsorption of the immobilized catalyst onto the cotton support would lead to lower conversion rates due to the activity reduction. Moreover, since an heterogeneous support is used, the mass transfer phenomena

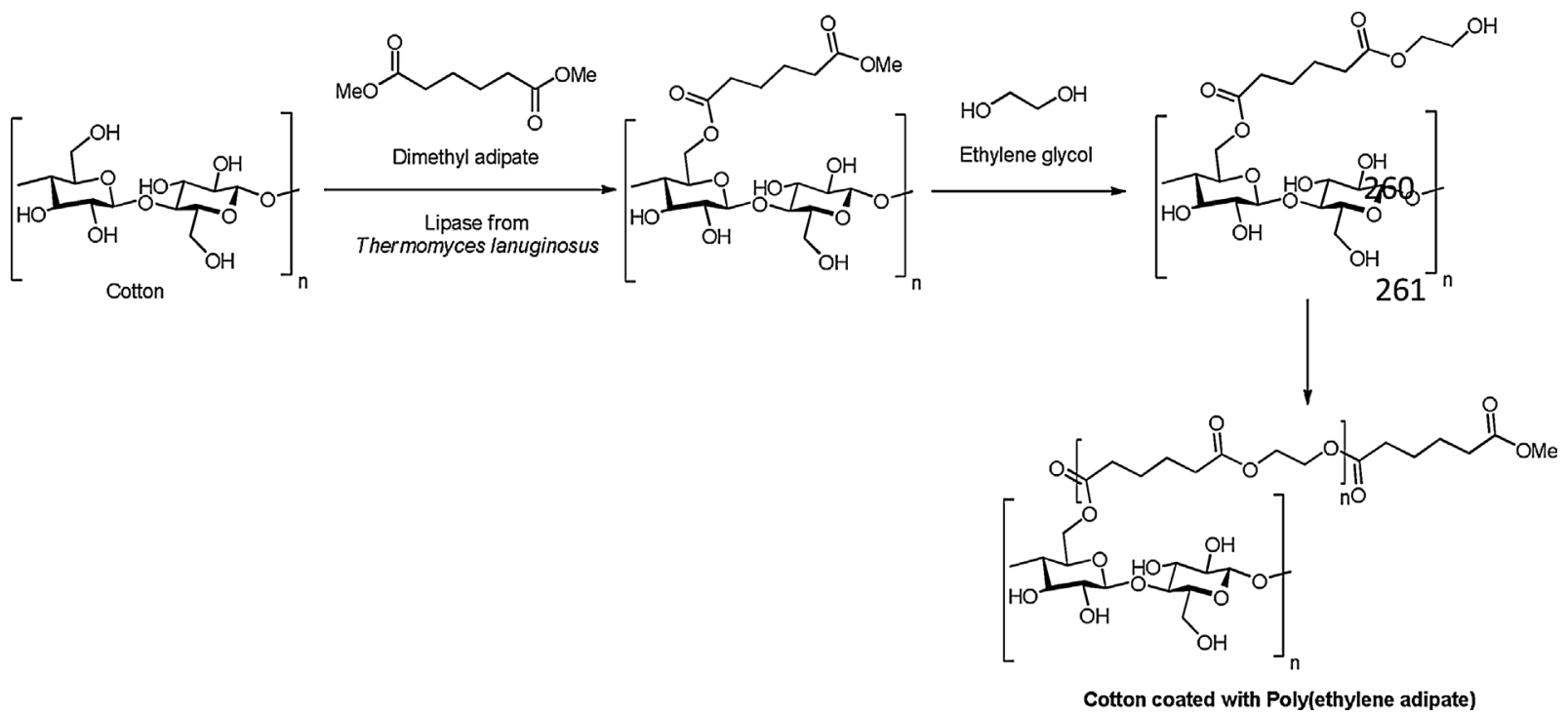

Fig. 1. Schematic representation of the in situ coating of cotton with poly(ethylene adipate). 
Table 5

The optimum reaction conditions and contact angle for each reaction scheme according to the orthogonal experimental design results ${ }^{1}$

\begin{tabular}{|c|c|c|c|}
\hline Reaction scheme & $\begin{array}{l}\text { The optimum } \\
\text { conditions }\end{array}$ & Contact angle $\left({ }^{\circ}\right)$ & Contact angle image \\
\hline $\begin{array}{c}\mathrm{A}_{0} \text {-Poly(ethylene } \\
\text { adipate) }\end{array}$ & $\begin{array}{l}\mathrm{C}_{3} \mathrm{~B}_{2} \mathrm{~A}_{2}-\mathrm{Vac} 8 \mathrm{~h}, \\
\underline{50 \%(\mathrm{v} / \mathrm{w}) \text { lipase, }} \\
\underline{45^{\circ} \mathrm{C}}\end{array}$ & $111.99( \pm 3.61)$ & \\
\hline $\begin{array}{c}\mathrm{B}_{0}-\text { Poly(ethylene } \\
\text { succinate) }\end{array}$ & $\begin{array}{l}\mathrm{A}_{3} \mathrm{C}_{3} \mathrm{~B}_{1}-\underline{55^{\circ} \mathrm{C}, \mathrm{Vac}} \\
\underline{8} \underline{\mathrm{h}, 35 \%(\mathrm{v} / \mathrm{w})} \\
\underline{\text { lipase }}\end{array}$ & $136.89( \pm 2.76)$ & \\
\hline $\begin{array}{c}\mathrm{C}_{0}-\text { Poly(glycerol } \\
\text { adipate) }\end{array}$ & $\begin{array}{l}\mathrm{C}_{3} \mathrm{~B}_{2} \mathrm{~A}_{2}-\mathrm{Vac} 8 \mathrm{~h}, \\
\underline{50 \%(\mathrm{~h} / \mathrm{w}) \text { lipase, }} \\
\underline{45^{\circ} \mathrm{C}}\end{array}$ & $130.05( \pm 4.98)$ & \\
\hline $\begin{array}{c}\mathrm{D}_{0}-\text { Poly(glycerol } \\
\text { succinate) }\end{array}$ & $\begin{array}{l}\mathrm{C}_{2} \mathrm{~B}_{2} \mathrm{~A}_{1}-\mathrm{Vac} 6 \mathrm{~h}, \\
\underline{50 \%(\mathrm{~V} / \mathrm{w}) \text { lipase, }} \\
\underline{35^{\circ} \mathrm{C}}\end{array}$ & $132.40( \pm 1.80)$ & \\
\hline
\end{tabular}

The numbers 1, 2 and 3 represent the levels for each factor (See Table 3); the order of the three factors A, B, C describe the decreasing influence degree of the factors on the water contact angle.

hindrance would be intensified by the use a solid catalyst.

An orthogonal experimental design L9 $(3 \times 3)$ was exploited to find the optimum conditions for the cotton surface coating. Three factors including temperature (A), enzyme loading (B) and reaction time (C) were considered and the index was the contact angle. The orthogonal experimental design and the results obtained for each reaction scheme are shown in the supplementary material section (Table S5-Table S8). The water contact angle of the coated cotton fabrics was measured using a Drop Shape Analyzer (DSA25, KRUSS GmbH, Germany) at room temperature. The best experimental conditions for each reaction scheme and the corresponding water contact angle are all displayed in Table 5. The water contact angles for the related control reactions with inactive enzyme and the original cotton were all zero degree, and for this reason are not shown in Table 5. The weight of cotton before and after coating was recorded, and the values were considered for the calculation of the coating yield (Table 5).

The optimum conditions obtained for the in situ coating of cotton by orthogonal design are different depending on the starting reactants.
They vary in terms of vacuum (6-8 h), amount of enzyme (35-50\%) and temperature $\left(35-45^{\circ} \mathrm{C}\right)$ and gave rise to different hydrophobicity performance. The water contact angle values of the coated samples were all higher than that obtained for cotton previously coated with poly (ethylene glutarate) $\left(127.01^{\circ}\right)$ [8] with exception of cotton coated with poly(ethylene adipate) (Reaction Scheme $\mathrm{A}_{0}$ ). The water repellency was remarkably improved using the conditions described herein. The coating yield for each reaction scheme varied from $2.5 \%$ to $4.6 \%$, but is not directly related with the final water contact angle values. The final water repellency will depend not only on the amount of polymer at the surface of the cotton fabric but also on the homogeneity of the coating.

For the in situ coating with poly(ethylene succinate) (Reaction Scheme $\mathrm{B}_{0}$ ) the optimal conditions established were: $55^{\circ} \mathrm{C}$ under $8 \mathrm{~h}$ of vacuum with $35 \%(\mathrm{v} / \mathrm{w})$ of soluble lipase. This scheme revealed the highest water contact angle after coating, $136.89^{\circ} \pm 2.76^{\circ}$ and a coating yield of $3.01 \%$. In this case, the temperature played the most important role for the in situ enzymatic synthesis of poly(ethylene succinate) by the orthogonal experiment analysis. The temperature promoted the opening of the fibre structure, incrementing the amount of polyester deposited at the surface of cotton, which resulted in a more hydrophobic surface. In all cases, the liquid state of the reactant substrates and the lipase seems also to favor the adsorption to the cotton fibres benefiting the in-situ polymerization of the polyesters and their attachment to the surface.

It is noteworthy that the time of vacuum can be decreased in $2 \mathrm{~h}$ as well as the temperature of reaction (Reaction Scheme $\mathrm{D}_{0}$ ) for poly (glycerol succinate). The results of water contact angle are still high $\left(132.40^{\circ} \pm 1.80^{\circ}\right)$ even with a lower coating yield $(2.51 \%)$ when compared with the scheme $B_{0}$. The reduction of the reaction time showed a great impact on the in situ polymerization of cotton, however obtained with a higher enzyme dosage.

Overall the in situ enzymatic polymerization of hydrophobic oligomers impart to cotton surface excellent hydrophobicity. In all the cases tested, the samples acquired a hydrophobic behavior.

The bromophenol blue water-drop test was used to provide a visualized proof of the hydrophobic behavior of the coated cotton samples (Fig. 2). From the results obtained after drop-testing, it can be observed that all coated cotton samples could hold the blue water-drop for at least $10 \mathrm{~s}$ without any absorption. Samples $\mathrm{A}_{0}$ and $\mathrm{B}_{0}$ retained the water drop intact for at least 50 s., demonstrating clear hydrophobic behavior, meanwhile samples $\mathrm{C}_{0}$ and $\mathrm{D}_{0}$ presented slightly different

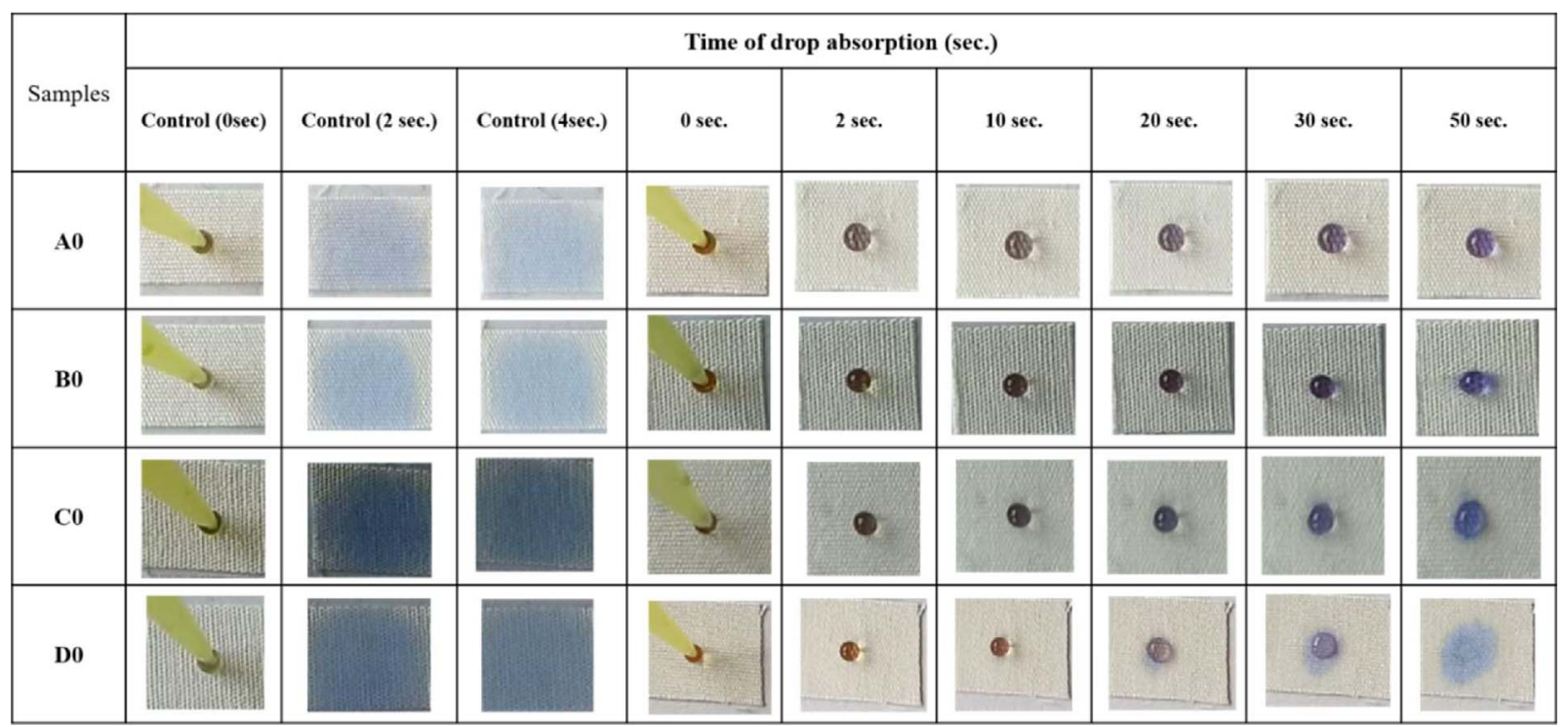

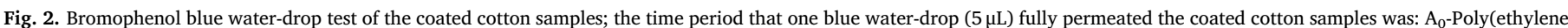

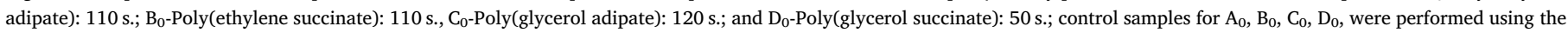
same conditions using deactivated lipase. (For interpretation of the references to colour in this figure legend, the reader is referred to the web version of this article). 
behavior, being detected some absorption from $30 \mathrm{~s}$. of exposure, being totally absorbed after $50 \mathrm{~s}$. on sample $\mathrm{D}_{0}$. In this case, a higher water contact angle did not correspond exactly to a higher time of water absorption. The wetting behavior could be, in this case, influenced by the lack of coating homogeneity with the new synthesized polyester. As previously described by NMR evaluation, the conversion rate of this new polyester was low, which might influence the final cotton coating and consequently the final hydrophobicity of the samples.

The fastness to washing of the coated samples can be predicted as high regarding the washing steps performed after coating. The samples suffer two washing cycles with organic solvents in which all the content on starting reactants and enzyme are removed. The remaining products, which confer hydrophobic behavior to the surfaces, give us an indication of further fastness resistance. Being hydrophobic, these polymers are not expected to be easily washed-out.

\section{Conclusions}

Poly(ethylene adipate), poly(ethylene succinate), poly(glycerol adipate) and poly(glycerol succinate) were successfully synthesized at $70{ }^{\circ} \mathrm{C}$ for $6 \mathrm{~h}$ under vacuum. The reactions were catalyzed by the immobilized CALB in the absence of solvents being the highest conversion obtained for the synthesis of poly(ethylene adipate) (88.5\%). Oligomers, mostly dimers and trimers, were detected by MALDI-TOF mass spectra. Hydrophobic cotton fabrics were obtained by in situ synthesis of polyesters using soluble lipase from Thermomyces lanuginosus as catalyst. After orthogonal processing optimization, it was possible to produce cotton surfaces with hydrophobic behavior. The in situ synthesis of poly(ethylene succinate) onto cotton surface impart the highest values of water contact angle, also confirmed by drop test analysis.

The work developed presents a new bio-approach to obtain hydrophobic cotton surfaces with potential for several applications like textiles, construction, among others.

\section{Acknowledgement}

This work was supported by Chinese government scholarship under the State Scholarship Fund (grant number 201706790049), Jiangsu Province Scientific Research Innovation Project for Academic Graduate Students (grant number KYLX16_0788), Training Fund for Excellent Doctoral Student in Jiangnan University, Key Projects of governmental cooperation in international scientific and technological innovation (grant number 2016 YFE0115700) and the National Key R \& D Program of China (grant number 2017 YFB0309100). This work was also supported by the Portuguese Foundation for Science and Technology (FCT) under the scope of the strategic funding of UID/BIO/04469/2013 unit and COMPETE 2020 (grant number POCI-01-0145-FEDER-006684) and under the Project RECI/BBB-EBI/0179/2012 (grant number FCOMP01-0124-FEDER-027462). This study was also supported by BioTecNorte operation (grant number NORTE-01-0145-FEDER000004) funded by the European Regional Development Fund under the scope of Norte2020 - Programa Operacional Regional do Norte. This work was also supported by the National Natural Science Foundation of China (grant number 31470509 and 31201134), the Industry-Academic Joint Technological Prospective Fund Project of Jiangsu Province (grant number BY2013015-24 and BY2016022-23), the fundamental research funds for the central universities (grant number JUSRP 51622A), and a project funded by the Priority Academic Program Development of Jiangsu Higher Education Institutions.

\section{Appendix A. Supplementary data}

Supplementary data associated with this article can be found, in the online version, at https://doi.org/10.1016/j.procbio.2018.01.002.

\section{References}

[1] U. Chanshetti, Green chemistry environmentally benign chemistry, Int. J. Adv. Res Chem. Sci. 1 (1) (2014) 110-115.

[2] B. Yeniad, H. Naik, A. Heise, Lipases in polymer chemistry, Adv. Biochem. Eng. Biotechnol. 125 (2011) 69-95.

[3] J. Zhang, H. Shi, D. Wu, Z. Xing, A. Zhang, Y. Yang, Q. Li, Recent developments in lipase-catalyzed synthesis of polymeric materials, Process Biochem. 49 (5) (2014) 797-806.

[4] K. Koeller, C. Wong, Enzymes for chemical synthesis, Nature 409 (6817) (2001) 232-240.

[5] P.D. Tomke, X. Zhao, P.P. Chiplunkar, B. Xu, H. Wang, C. Silva, V.K. Rathod, A. Cavaco-Paulo, Lipase-ultrasound assisted synthesis of polyesters, Ultrason. Sonochem. 38 (Suppl. C) (2017) 496-502.

[6] J. Yi, K. Loos, Enzymatic synthesis of biobased polyesters and polyamides, Polymers 8 (7) (2016) 1-53 20734360.

[7] A. Díaz, R. Katsarava, J. Puiggalí, Synthesis, Properties and applications of biodegradable polymers derived from diols and dicarboxylic acids: from polyesters to poly(ester amide)s, Int. J. Mol. Sci. 15 (5) (2014) 7064-7123.

[8] X. Zhao, J. Fu, H. Wang, A. Ribeiro, A. Cavaco-Paulo, Enzymatic coating of cotton with poly (ethylene glutarate), Process Biochem. 59 (Pt. A) (2017) 91-96.

[9] V. Delplace, J. Nicolas, Degradable vinyl polymers for biomedical applications, Nat. Chem. 7 (10) (2015) 771-784.

[10] H. Seyednejad, A.H. Ghassemi, C.F. van Nostrum, T. Vermonden, W.E. Hennink, Functional aliphatic polyesters for biomedical and pharmaceutical applications, J. Control. Release 152 (1) (2011) 168-176.

[11] M.A. Hillmyer, W.B. Tolman, Aliphatic polyester block polymers: renewable, degradable, and sustainable, Acc. Chem. Res. 47 (8) (2014) 2390-2396.

[12] M. Vert, S.M. Li, G. Spenlehauer, P. Guerin, Bioresorbability and biocompatibility of aliphatic polyesters, J. Mater. Sci. Mater. Med. 3 (6) (1992) 432-446.

[13] Y. Yu, D. Wu, C. Liu, Z. Zhao, Y. Yang, Q. Li, Lipase/esterase-catalyzed synthesis of aliphatic polyesters via polycondensation: a review, Process Biochem. 47 (7) (2012) 1027-1036.

[14] P.-Y. Stergiou, A. Foukis, M. Filippou, M. Koukouritaki, M. Parapouli, L.G. Theodorou, E. Hatziloukas, A. Afendra, A. Pandey, E.M. Papamichael, Advances in lipase-catalyzed esterification reactions, Biotechnol. Adv. 31 (8) (2013) 1846-1859.

[15] L.R. Gerits, B. Pareyt, K. Decamps, J.A. Delcour, Lipases and Their Functionality in the production of wheat-based food systems, Compr. Rev. Food Sci. Food Saf. 13 (5) (2014) 978-989.

[16] S.C.B. Gopinath, P. Anbu, T. Lakshmipriya, A. Hilda, Strategies to characterize fungal lipases for applications in medicine and dairy industry, BioMed Res. Int. 2013 (2013) 154549.

[17] S.K. Bhangu, S. Gupta, M. Ashokkumar, Ultrasonic enhancement of lipase-catalysed transesterification for biodiesel synthesis, Ultrason. Sonochem. (Suppl. C) (2017) 305-309 34.

[18] S.R. Bansode, V.K. Rathod, An investigation of lipase catalysed sonochemical synthesis: a review, Ultrason. Sonochem. 38 (Suppl. C) (2017) 503-529.

[19] A. Salihu, M.Z. Alam, Solvent tolerant lipases: a review, Process Biochem. 50 (1) (2015) 86-96.

[20] L. Ma, L. Zhou, Y. Jiang, Y. He, L. Wang, J. Gao, Lipase based static emulsions as efficient biocatalysts for biodiesel production, J. Chem. Technol. Biotechnol. 92 (6) (2017) 1248-1255.

[21] V.K. Garlapati, R. Banerjee, Solvent-free synthesis of flavour esters through immobilized lipase mediated transesterification, Enzyme Res. (2013) 1-6.

[22] M. Ćorović, M. Mihailović, K. Banjanac, M. Carević, A. Milivojević, N. Milosavić, D. Bezbradica, Immobilization of Candida antarctica lipase B onto purolite" MN102 and its application in solvent-free and organic media esterification, Bioprocess Biosyst. Eng. 40 (1) (2017) 23-34.

[23] J. Song, O.J. Rojas, Approaching super-hydrophobicity from cellulosic materials: a review, Nord. Pulp Paper Res. J. 28 (2) (2013) 216-238.

[24] V.V. Klimov, E.V. Bryuzgin, M.D. Le, E.A. Zelenova, T.H. Nguyen, A.V. Navrotskii, H. Nishide, I.A. Novakov, An investigation of the hydrophobic property stability of grafted polymeric coatings on a cellulose material surface, Polym. Sci. Ser. D 9 (4) (2016) 364-367.

[25] M. Zahid, J.A. Heredia-Guerrero, A. Athanassiou, I.S. Bayer, Robust water repellent treatment for woven cotton fabrics with eco-friendly polymers, Chem. Eng. J. 319 (Suppl. C) (2017) 321-332.

[26] A. Ramamoorthy, A. El-Shafei, P. Hauser, Plasma induced graft polymerization of c6 fluorocarbons on cotton fabrics for sustainable finishing applications, Plasma Process. Polym. 10 (5) (2013) 430-443.

[27] M. Przybylak, H. Maciejewski, A. Dutkiewicz, D. Wesołek, M. Władyka-Przybylak, Multifunctional, strongly hydrophobic and flame-retarded cotton fabrics modified with flame retardant agents and silicon compounds, Polym. Degrad. Stab. 128 (Suppl. C) (2016) 55-64.

[28] X. Zhao, S.R. Bansode, A. Ribeiro, A.S. Abreu, C. Oliveira, P. Parpot, P.R. Gogate, V.K. Rathod, A. Cavaco-Paulo, Ultrasound enhances lipase-catalyzed synthesis of poly (ethylene glutarate), Ultrason. Sonochem. 31 (Suppl. C) (2016) 506-511.

[29] A. Idris, A. Bukhari, Immobilized Candida antarctica lipase B: hydration, stripping off and application in ring opening polyester synthesis, Biotechnol. Adv. 30 (3) (2012) 550-563.

[30] Z. Xiaoman, M. Teresa, R. Artur, S. Carla, W. Jing, F. Jiajia, C.-P. Artur, Cutinase promotes dry esterification of cotton cellulose, Biotechnol. Prog. 32 (1) (2016) $60-65$.

[31] A.M. Stepan, G.E. Anasontzis, T. Matama, A. Cavaco-Paulo, L. Olsson, 
P. Gatenholm, Lipases efficiently stearate and cutinases acetylate the surface of arabinoxylan films, J. Biotechnol. 167 (1) (2013) 16-23.

[32] J. Yang, M. Zhang, Effect of monomer carbon number on synthesis of straight-chain polyester catalyzed by lipase N435, China Synth. Resin Plast. 30 (1) (2013) 48-51.

[33] C. Laane, S. Boeren, K. Vos, C. Veeger, Rules for optimization of biocatalysis in organic solvents, Biotechnol. Bioeng. 30 (10) (1986) 81-87.
[34] H. Azim, A. Dekhterman, Z. Jiang, R.A. Gross, Candida Antarctica lipase B-catalyzed synthesis of poly(butylene succinate): shorter chain building blocks also work, Biomacromolecules 7 (11) (2006) 3093-3097.

[35] T. Matamá, M. Casal, A. Cavaco-Paulo, Direct enzymatic esterification of cotton and avicel with wild-type and engineered cutinases, Cellulose 20 (1) (2013) 409-416. 